\title{
Effect of curing conditions on long term mechanical property of improved surplus soils
}

\author{
Yukika Miyashita ${ }^{1, *}$, Dayani Sanjeewani ${ }^{2}$, and Reiko Kuwano ${ }^{2}$ \\ ${ }^{1}$ Public Works Research Institute, Geology and Geotechnical Engineering Research Group, 1-6 Minamihara, Tsukuba, Ibaraki, Japan \\ ${ }^{2}$ Institute of Industrial Science, the University of Tokyo, 4-6-1 Komaba, Meguro-ku, Tokyo, Japan
}

\begin{abstract}
In this study, the effect of environmental exposure conditions on the long term mechanical property of surplus soils improved by lime and cement was investigated by conducting unconfined compression tests on the specimens cured under different conditions. As the result of the experiments after about 1 year (336 days) from specimen preparation, the unconfined compressive strengths of the soaked specimens were found to be the smallest, while those of the sealed specimens were the largest. Effect of soaking on the strengths appeared obviously in the cement treated soil, while the effect decreased when the duration of initial sealed curing increased. It was inferred that these differences in the strengths were caused by the changes in physical properties such as degree of saturation, and chemical properties due possibly to the leaching of hydration products during soaked curing.
\end{abstract}

\section{Introduction}

In Japan, it has been promoted to utilize surplus soils which are generated by earthworks such as cutting and excavations. Currently, about $90 \%$ of the whole soils employed in earthworks have been occupied by surplus soils, according to the survey of construction by-product which was conducted by the Ministry of Land, Infrastructure, Transport and Tourism, Japan in 2012. The surplus soils with less strength or trafficability have been adopted to use by applying chemical stabilization using lime or cement. These improved soils have been used frequently as fill materials of road embankments.

The durability and stability of the road embankments are affected by the change in the long term mechanical properties of the improved soil. As schematically shown in Fig. 1, effect of water infiltration caused by rainfall and ground water would not be negligible on the mechanical property of the improved soil, whose binder content is smaller and permeability is higher than the improved soils by deep mixing method [1-4]. In general, it is well known that the strength of the improved soils increase with the curing period under controlled laboratory conditions, due to the chemical reactions between soil and binders. However, according to the site investigation conducted on a high embankment in Japan, unconfined compressive strength at a certain depth below the ground water level was hardly increased from the strength nine years ago [5].

In this study, the effect of environmental exposure conditions on the long term mechanical property of improved soils was investigated. Lime and cement improvement were applied to a sandy soil with changing their contents. Specimens of those soils have been cured under sealed and soaked conditions. Unconfined compression tests were conducted periodically until 1 year, while measuring physical and chemical properties of the specimens. Difference in the mechanical properties of them under sealed and soaked curing was discussed, based on the change in their physical and chemical properties.

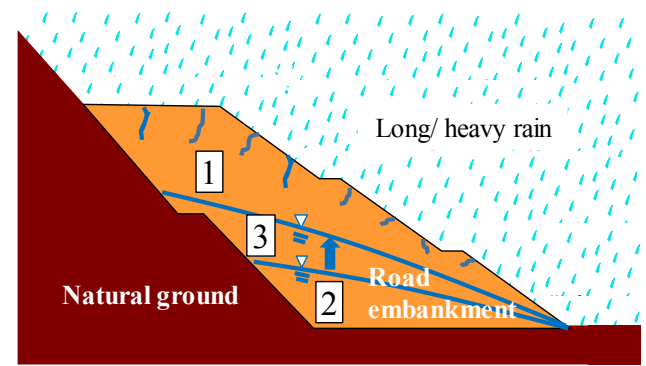

Fig. 1. Schematic figure of environmental exposure conditions in road embankment.

\section{Materials and testing procedures}

\subsection{Materials and procedures of specimen preparation}

A sand with fines which is called hereafter as Miho sand was used in this study. Physical and mechanical properties of Miho sand are summarized in Table. 1. Grain size distribution of Miho sand is presented in Fig. 2. Miho sand was obtained from a mountain in Ibaraki prefecture, Japan, with its natural water content of approximately 31 $\%$. Quality of Miho sand was similar to those of typical surplus soils having low strength, as indicated with the cone index in Table 1. Two types of binders, quick lime (denoted hereafter as lime) and a cement-based product

\footnotetext{
* Corresponding author: y-miyashita@pwri.go.jp
} 
were employed to improve the quality of Miho sand. The cement-based product denoted hereafter as cement was developed in Japan to make the effectiveness against low quality soils higher than that of Ordinary Portland Cement.

The contents of lime were set to $1.2,2.5$ and $3.8 \%$ by dried weight of Miho sand, while those of the cement were set to $1.7,3.5$ and $5.3 \%$. The middle contents of lime and cement were decided by considering the 7 days unconfined compressive strength as of $100 \mathrm{kN} / \mathrm{m}^{2}$. These low contents of lime and cement coincided with the minimum values which were empirically recommended in the manuals published by Japan Lime Association (JLA) and Japan Cement Association (JCA), respectively [6-7]. The smaller and larger contents of lime and cement were simply set to be 0.5 and 1.5 times of the middle contents to investigate the effect of the binder contents. The water content of Miho sand was set to $31 \%$. One of the binders and Miho sand were mixed uniformly by a soil mixer for 5 minutes. Cylindrical specimens with $50 \mathrm{~mm}$ in diameter and $100 \mathrm{~mm}$ in height were prepared by applying static compaction. Dry density of the specimens was set to 1.4 $\mathrm{g} / \mathrm{cm}^{3}$, by referring to the result of large scale model tests to investigate the characteristics of compaction using actual construction machines.

Table 1. Physical and mechanical properties of Miho sand.

\begin{tabular}{|c|c|}
\hline Soil type & Sand with fines \\
\hline Specific gravity, $\rho_{\mathrm{s}}$ & 2.693 \\
\hline Plasticity index, $\mathrm{I} \mathrm{P}$ & 25.4 \\
\hline Optimum water content, $\mathrm{w}_{\mathrm{opt}}(\%)$ & 21.6 \\
\hline Maximum dry density, $\rho_{\mathrm{dmax}}\left(\mathrm{g} / \mathrm{cm}^{3}\right)$ & 1.624 \\
\hline $\begin{array}{c}\text { Cone index, } \mathrm{q}_{\mathrm{c}}\left(\mathrm{kN} / \mathrm{m}^{2}\right) \\
\text { (with water content of } 31 \%)\end{array}$ & 68 \\
\hline
\end{tabular}

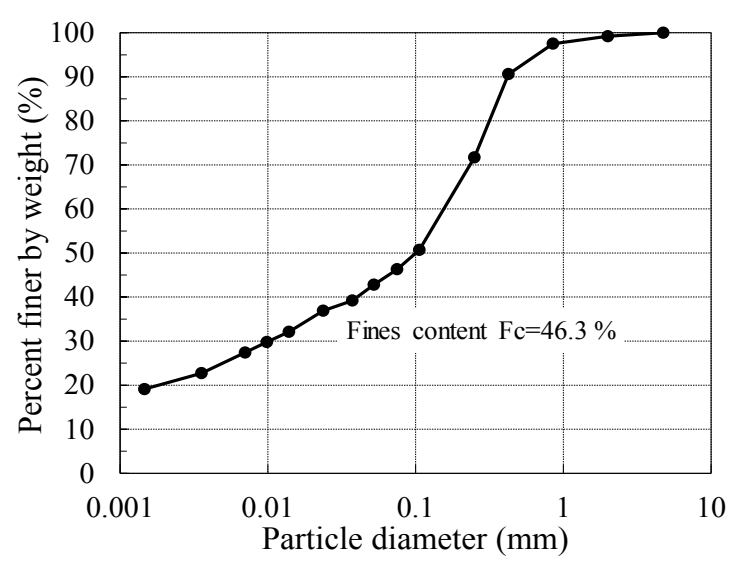

Fig. 2. Grain size distribution of Miho sand.

\subsection{Curing conditions}

All specimens were cured under three different curing conditions as schematically shown in Fig. 3. In case 1 which is called hereafter as sealed curing, specimens were wrapped with plastic sheet to avoid moisture transportation. To evaluate the effect of soaking from early curing period on the strength, the second set of specimens were cured under pure water or artificially made acidic water, after applying sealed curing for initial
3 days. It was classified as soaked curing (case 2). The last set of specimens were cured under sealed condition for initial 6 months (168 days), followed by the soaked curing under the acidic water (case 3 ). Case 3 was designed to simulate the possible deterioration of improved soil after gaining strength fully, due to the increase of ground water level or water infiltration through cracks or other water paths in the embankment. A constant temperature within the range of 17 to 23 degrees Celsius was kept in all of the cases.

$\mathrm{pH}$ value of the acidic water was set to 4.5 by mixing pure water with sulfuric acid $\left(\mathrm{H}_{2} \mathrm{SO}_{4}\right)$, nitric acid $\left(\mathrm{HNO}_{3}\right)$ and hydrochloric acid $(\mathrm{HCl})$ by $5: 2: 3$ proportionally to simulate the actual acid rain in Japan. The volume ratio of a specimen and water soaking was set to 1:5. In the initial 28 days, the water soaking was exchanged once a week. Duration for the exchange was increased to 2 weeks until 168 days, while it was increased again to 4 weeks after 168 days.

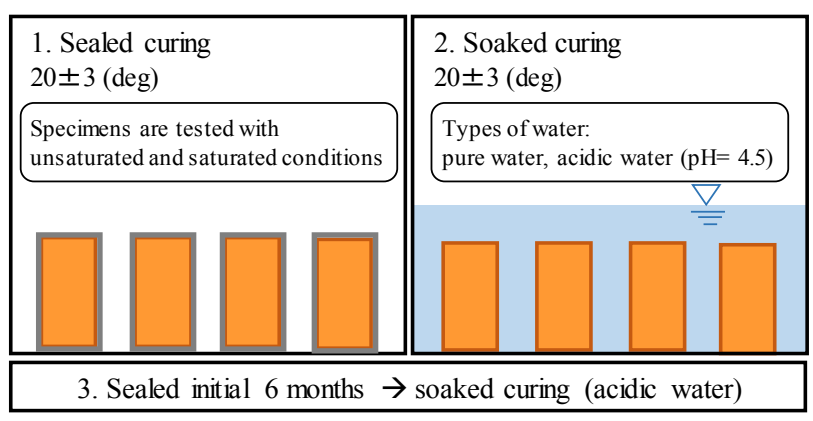

Fig. 3. Schematic figure of curing conditions in laboratory.

\subsection{Procedure of mechanical and chemical tests}

Unconfined compression tests (JIS A 1216) were conducted on the specimens cured in the cases 1 and 2 after 7, 28, 168 and 336 days from their preparation. The specimens cured in the case 3 were tested after 175, 196 and 336 days, while these periods coincided with 7, 28 and 168 days after starting soaking. In every curing periods, three specimens cured in the case 1 were saturated by applying vacuum pressure under pure water 1 day prior to the corresponding curing date, whereas another three specimens were tested as they were. Types and contents of the binders, conditions of curing and specimens when tested, and types of water for soaked curing were organized in Table 2 with indicating their notation abbreviated in this paper. It should be mentioned that a series of needle penetration tests have also been conducted simultaneously to understand the progression of deterioration of the improved surplus soils under soaked condition [8].

The water after soaking from the cases 2 and 3 was collected to measure $\mathrm{pH}$ value, concentrations of $\mathrm{Ca}$ and $\mathrm{SO}_{4} . \mathrm{pH}$ value was measured by glass electrode method using a compact analyser (Horiba LAQUA twin B-712). Concentration of $\mathrm{Ca}$ was obtained by ion electrode method using another compact analyser (Horiba LAQUA twin B-715). Concentration of $\mathrm{SO}_{4}$ was quantified by ion chromatography (JIS K 0102 41.3). X-ray Fluorescence analyses (denoted hereafter as XRF) were applied to Miho 
sand, lime and cement. Chemical components of them are presented in Table $3 . \mathrm{SO}_{3}$ in the cement was analysed by wet chemistry (JIS R 5202). severe acidic conditions were reported in the previous studies [9-10].

Relationships between $\mathrm{q}_{\mathrm{u}}$ values of soils treated by

Table 2. Types and contents of the binders, conditions of curing and specimens when tested, and types of water for soaked curing.

\begin{tabular}{|c|c|c|c|c|}
\hline Binders & Binder contents & Curing conditions & $\begin{array}{c}\text { Types of water/ } \\
\text { specimen conditions }\end{array}$ & $\begin{array}{c}\text { Notations } \\
\text { abbreviated }\end{array}$ \\
\hline \multirow{11}{*}{$\begin{array}{l}\text { Quick } \\
\text { lime } \\
\text { (Lime) }\end{array}$} & \multirow{3}{*}{$3.8 \%$} & \multirow{2}{*}{ Sealed } & Unsaturated & L3.8Seal(unsat) \\
\hline & & & Saturated & L3.8Seal(sat) \\
\hline & & Soaked & Acidic water & L3.8Soak(acid) \\
\hline & \multirow{5}{*}{$\begin{array}{c}2.5 \% \\
\text { (target } \mathrm{qu}_{\mathrm{u}} \text { as of } \\
100 \mathrm{kN} / \mathrm{m}^{2} \\
\text { after } 7 \text { days) }\end{array}$} & \multirow{2}{*}{ Sealed } & Unsaturated & L2.5Seal(unsat) \\
\hline & & & Saturated & L2.5Seal(sat) \\
\hline & & \multirow{2}{*}{ Soaked } & Pure water & L2.5Soak(pure) \\
\hline & & & Acidic water & L2.5Soak(acid) \\
\hline & & Soaked after sealed in 6 months & Acidic water & L2.5Seal $\rightarrow$ soak (acid) \\
\hline & \multirow{3}{*}{$1.2 \%$} & \multirow{2}{*}{ Sealed } & Unsaturated & L3.8Seal(unsat) \\
\hline & & & Saturated & L3.8Seal(sat) \\
\hline & & Soaked & Acidic water & L3.8Soak(acid) \\
\hline \multirow{11}{*}{$\begin{array}{l}\text { Cement- } \\
\text { based } \\
\text { product } \\
\text { (Cement) }\end{array}$} & \multirow{3}{*}{$5.3 \%$} & \multirow{2}{*}{ Sealed } & Unsaturated & C5.3Seal(unsat) \\
\hline & & & Saturated & C5.3Seal(sat) \\
\hline & & Soaked & Acidic water & C5.3Soak(acid) \\
\hline & \multirow{5}{*}{$\begin{array}{c}3.5 \% \\
\text { (target } \mathrm{qu}_{\mathrm{u}} \text { as of } \\
100 \mathrm{kN} / \mathrm{m}^{2} \\
\text { after } 7 \text { days) }\end{array}$} & \multirow{2}{*}{ Sealed } & Unsaturated & C3.5Seal(unsat) \\
\hline & & & Saturated & C3.5Seal(sat) \\
\hline & & \multirow{2}{*}{ Soaked } & Pure water & C3.5Soak(pure) \\
\hline & & & Acidic water & C3.5Soak(acid) \\
\hline & & Soaked after sealed in 6 months & Acidic water & C3.5Seal $\rightarrow$ soak(acid) \\
\hline & \multirow{3}{*}{$1.7 \%$} & \multirow{2}{*}{ Sealed } & Unsaturated & C1.7Seal(unsat) \\
\hline & & & Saturated & C1.7Seal(sat) \\
\hline & & Soaked & Acidic water & C1.7Soak(acid) \\
\hline
\end{tabular}

Table 3. Chemical components of Miho sand, lime and cement.

\begin{tabular}{|c|c|c|c|c|c|c|c|c|c|c|c|c|}
\hline & $\begin{array}{c}\mathrm{SiO}_{2} \\
(\mathrm{wt} \%)\end{array}$ & $\begin{array}{c}\mathrm{TiO}_{2} \\
(\mathrm{wt} \%)\end{array}$ & $\begin{array}{c}\mathrm{Al}_{2} \mathbf{O}_{3} \\
(\mathbf{w t} \%)\end{array}$ & $\begin{array}{l}\mathrm{Fe}_{2} \mathrm{O}_{3} \\
(\mathrm{wt} \%)\end{array}$ & $\begin{array}{l}\mathrm{MnO}_{2} \\
(\mathrm{wt} \%)\end{array}$ & $\begin{array}{c}\text { MgO } \\
\text { (wt\%) }\end{array}$ & $\begin{array}{c}\mathrm{CaO} \\
(\mathrm{wt} \%)\end{array}$ & $\begin{array}{l}\mathrm{Na}_{2} \mathrm{O} \\
(\mathrm{wt} \%)\end{array}$ & $\begin{array}{c}\mathrm{K}_{2} \mathrm{O} \\
(\mathrm{wt} \%)\end{array}$ & $\begin{array}{c}\mathrm{P}_{2} \mathrm{O}_{5} \\
(\mathrm{wt} \%)\end{array}$ & $\begin{array}{c}S_{\text {Statal }} \\
(w t \%)\end{array}$ & $\begin{array}{c}\mathrm{SO}_{3} \\
(w \mathrm{wt} \%)\end{array}$ \\
\hline Miho sand & 61.69 & 0.73 & 19.92 & 6.86 & 0.11 & 1.29 & 1.48 & 1.18 & 1.54 & 0.10 & 0.03 & - \\
\hline Lime & \multicolumn{6}{|c|}{ not measured } & 94.93 & \multicolumn{3}{|c|}{ not measured } & $<0.02$ & - \\
\hline Cement & \multicolumn{6}{|c|}{ not measured } & 56.37 & \multicolumn{3}{|c|}{ not measured } & 3.13 & 6.08 \\
\hline
\end{tabular}

\section{Results and discussion}

\subsection{Result of unconfined compression test}

Typical stress strain relationships of Miho sand treated by lime and cement after 336 days are shown in Fig. 4. The contents of lime and cement in Fig. 4 are 2.5 and 3.5\%, respectively. The highest unconfined compressive strength $\left(\mathrm{q}_{\mathrm{u}}\right)$ and largest strain at failure $\left(\varepsilon_{\mathrm{f}}\right)$ were obtained from the unsaturated specimen in the case 1, 'Seal(unsat)' among the lime treated specimens. $\mathrm{q}_{\mathrm{u}}$ and $\varepsilon_{\mathrm{f}}$ values of soaked specimens in the cases 2 and 3 were almost the same, while $\mathrm{q}_{\mathrm{u}}$ value of the saturated specimen in the case 1, 'Seal(sat)', was slightly larger than those of the soaked specimens. In the cement treated specimens, $\mathrm{q}_{\mathrm{u}}$ value was the highest in 'Seal(unsat)', followed in order by 'Seal(sat)', soaked specimens in the case 3 and those in the case 2 . Largest $\varepsilon_{\mathrm{f}}$ values were measured on the soaked specimens in the case 2, while indicating the lowest stiffness. In both lime and cement treatment, there was no clear difference in their stress strain relationships of the specimens under pure and acidic water in the case 2 , although the effect of soaking on the strengths under more lime and cement and curing period are summarized in Figs.5 and 6, respectively. Higher levels of $\mathrm{q}_{\mathrm{u}}$ values were obtained when the binder contents were larger. In every curing periods, $\mathrm{q}_{\mathrm{u}}$ values of 'Seal(unsat)' were the highest on each binder content. By applying saturation to the sealed specimens, $\mathrm{q}_{\mathrm{u}}$ values became lower than those of unsaturated specimens in all of the contents. It could be said that the strength of sealed specimens in the case 1 increased depending on the curing period, except for the improved soils with the minimum contents (L1.2 and C1.7).

In the lime treated soils, $\mathrm{q}_{\mathrm{u}}$ values of soaked specimens were almost the same as those of 'Seal(sat)' specimens in the early curing period, as shown in Fig. 5. Strengths of soaked specimens in the case 2 became slightly lower than those of 'Seal(sat)' specimens after 28 days in L1.2 and 168 days in L2.5. In the largest lime content, L3.8, strength of soaked specimens after 336 days decreased from 168 days. In other words, clear difference was observed from the strengths of the sealed specimens after 336 days in L3.8. There was no difference between the strengths of soaked specimens in the cases 2 and 3 after 336 days, irrespective of the different durations for sealed and soaked curing. 
In the cement treated soils, lower strengths than those of 'Seal(sat)' specimens were obtained from soaked specimens after 7 days in C1.7, 28 days in C3.5, and 168 days in C5.3, as shown in Fig. 6. That is, effect of the soaked curing in the case 2 appeared as the decrease in the strengths earlier, when the content of the cement was smaller. The strengths obtained from the case 2 were lower than those from the case 3 . It was confirmed from the difference that the effect of soaked curing was depending on the durations of initial sealing and soaking, in the case of cement treatment.
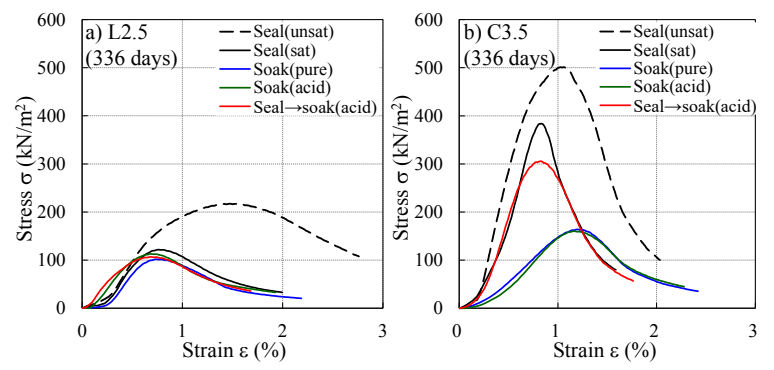

Fig. 4. Typical stress strain relationships of specimens treated by lime and cement after 336 days.

\subsection{Effect of physical properties on strengths}

To identify the effect of changes in physical properties on strengths properties as described in 3.1, relationships between strength ratio, dry density and degree of saturation $\left(\mathrm{S}_{\mathrm{r}}\right)$ were obtained. Fig. 7 represents the relationships of the lime treated soils after 28, 168 and 336 days, whereas Fig. 8 shows those of the cement treated soils.

The strength ratio was defined as the ratio of the averaged $\mathrm{q}_{\mathrm{u}}$ value in each condition to the averaged $\mathrm{q}_{\mathrm{u}}$ value in 'Seal(sat)' condition at a particular curing period. There was no distinct trend on the change in dry density except for $\mathrm{C} 1.7$, while exhibiting variations in every sets of specimens. On the other hand, levels of $S_{r}$ values in 'Seal(sat)' conditions were always higher than those of unsaturated conditions. It was inferred that the $\mathrm{q}_{\mathrm{u}}$ values of 'Seal(sat)' were lower due possibly to the decline of the strengths derived from suction force.

The strength ratios of the soaked specimens were close to 1 , while indicating same levels of $S_{r}$ values in the case of lime treated soils. Therefore, it could be roughly explained that the difference in $\mathrm{q}_{\mathrm{u}}$ values of soaked specimens in lime treatment from 'Seal(unsat)' occurred mainly due to reduction of the suction force, except for 'L3.8Soak(acid)' after 336 days. The decrease in the strength of 'L3.8Soak(acid)' after 336 days could not be understood only by evaluating the physical properties. Strength ratios on the soaked specimens treated by cement gradually decreased with the increase in the period of soaked curing, while achieving the same levels of $S_{r}$ values as 'Seal(sat)'. It was not possible to explain the difference in the strengths of soaked and 'Seal(sat)' conditions in cement treated soils only by the physical properties.
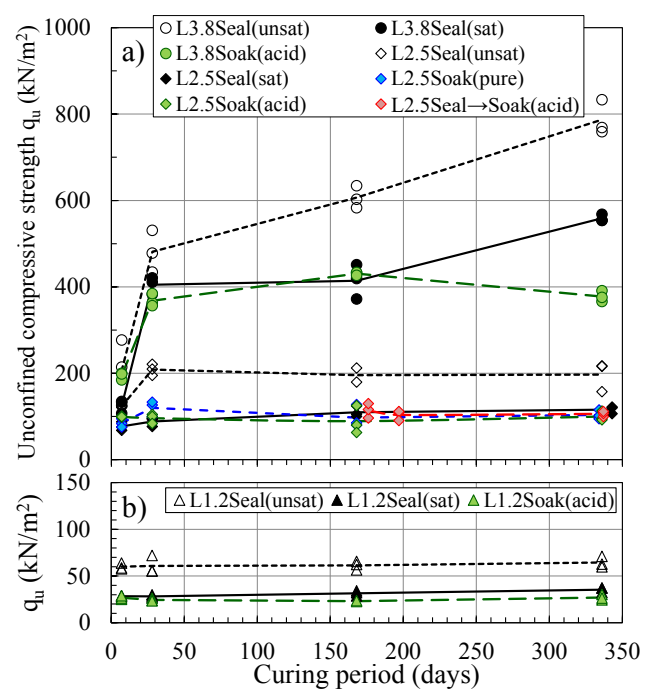

Fig. 5. Relationships between unconfined compressive strength of lime treated soils and curing period.

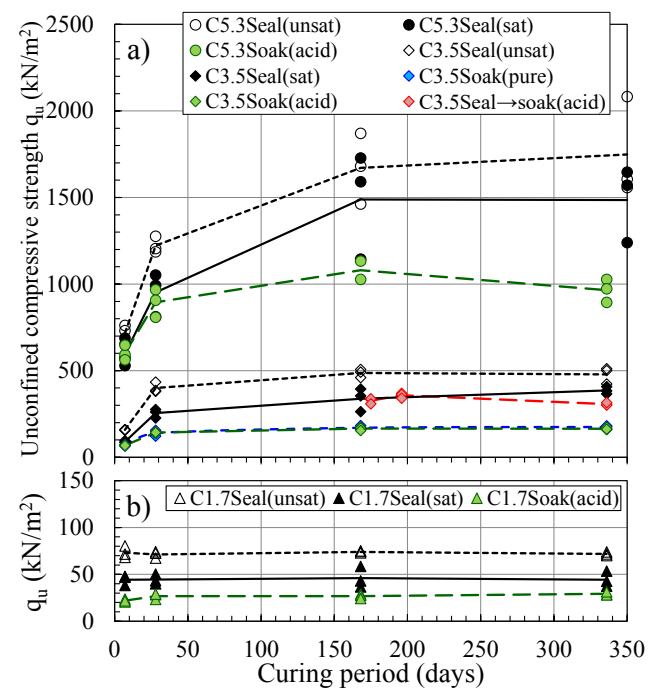

Fig. 6. Relationships between unconfined compressive strength of cement treated soils and curing period.
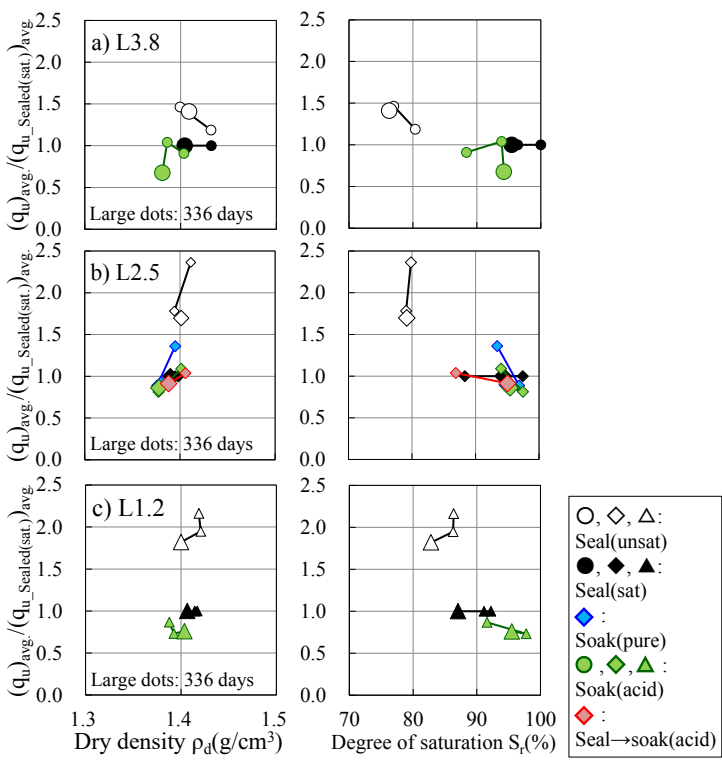

Fig. 7. Relationships between strength ratio, dry density and degree of saturation of lime treated soils. 


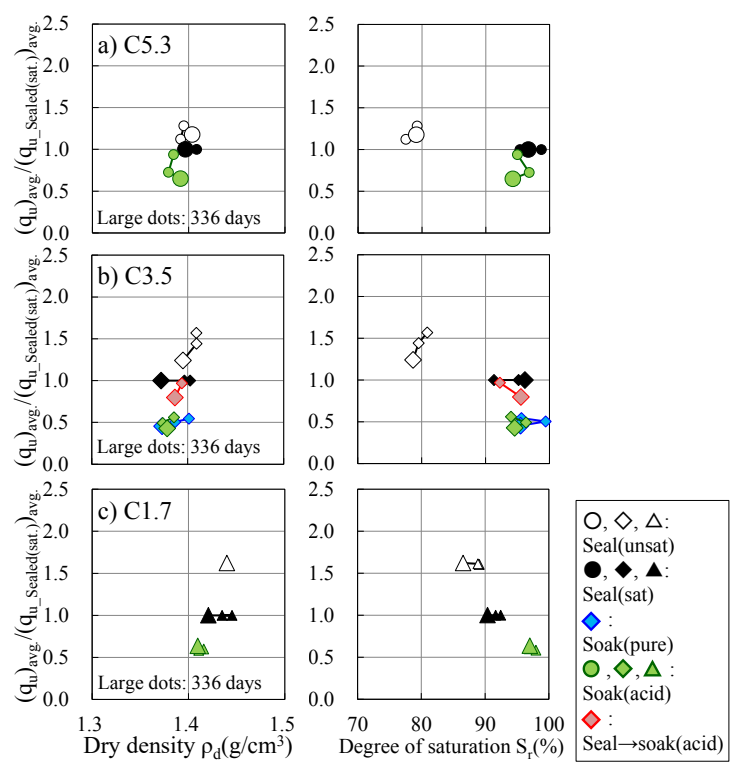

Fig. 8. Relationships between strength ratio, dry density and degree of saturation of cement treated soils.

It was difficult to make the sealed specimens of L1.2 and $\mathrm{C} 1.7$ saturated fully, as the strengths were not enough to apply vacuum pressure. Consequently in these 2 contents, difference in strengths between 'Seal(sat)' and soaked were actually affected by $\mathrm{S}_{\mathrm{r}}$ values. Therefore, it should be mentioned earlier that accurate evaluation of the effect of chemical properties on the strengths could not be achieved in these 2 contents.

\subsection{Effect of chemical properties on strengths}

Figs. 9 and 10 indicate the changes in $\mathrm{pH}$ value (a), accumulated amounts of $\mathrm{Ca}(\mathrm{b})$ and $\mathrm{SO}_{4}(\mathrm{c})$ which were measured on the collected water after soaking of the specimens, over the curing period. The amounts of accumulated $\mathrm{Ca}$ and $\mathrm{SO}_{4}$ coincided with the leached amounts from a single specimen. $\mathrm{pH}$ values of pure water and acidic water after soaked curing increased to alkaline conditions. Water under which L3.8 specimens were soaked indicated the highest $\mathrm{pH}$ value in the beginning, while the other $\mathrm{pH}$ values were varied in response to the types and contents of the binders. Gradual decreases in $\mathrm{pH}$ value were observed with the increase in the curing period in all of the cases. Among the measurement on the case 2, $\mathrm{pH}$ of L3.8 kept the highest value as 11, whereas the other $\mathrm{pH}$ values became less than 10 after 336 days. Larger $\mathrm{pH}$ values were kept in the case 3 curing than those in case 2 until 336 days.

Leaching rates of $\mathrm{Ca}$ and $\mathrm{SO}_{4}$ were the largest initially, while those were gradually decreased in all of the cases. In the case of lime treatment cured under the case 2, the amount of $\mathrm{Ca}$ leached was larger when the lime content was larger. It was estimated that the amount of $\mathrm{SO}_{4}$ leached in the lime treatment was obtained due to the leaching from the component of Miho sand. It should be noted that the original amount of $\mathrm{SO}_{4}$ in the acidic water was calculated as $0.51 \mathrm{mg} / \mathrm{L}$ and small enough to the measured values as leached amounts in Figs 9 c) and 10 c). In the case of cement treatment cured under the case 2 , the amount of $\mathrm{Ca}$ leached was almost the same in C5.3 and C3.5, while smaller accumulation was observed in C1.7. Leaching of $\mathrm{SO}_{4}$ was the largest in $\mathrm{C} 3.5$, followed in order by $\mathrm{C} 5.3$ and $\mathrm{C} 1.7$ at 336 days. As compared to the soaked curing in the case 2 until 168 days, smaller decrement in $\mathrm{pH}$, leaching of $\mathrm{Ca}$ and $\mathrm{SO}_{4}$ were obtained in the case 3 until 336 days which coincided with the same duration of soaking.

According to the chemical compositions of the binders as shown in Table 2, the representative amount of $\mathrm{Ca}$ in every single specimen due to the addition of lime or cement was calculated on each case. The difference between the amount of $\mathrm{Ca}$ added and leached divided by the amount of $\mathrm{Ca}$ added was calculated and defined as remaining ratio of $\mathrm{Ca}$ on the soaked specimens. Remaining ratio of $\mathrm{SO}_{4}$ were also calculated with the same manner as $\mathrm{Ca}$, while assuming that the component of $\mathrm{S}_{\text {total }}$ in the cement was derived from $\mathrm{SO}_{4}$. It was also assumed here that the leaching of $\mathrm{Ca}$ and $\mathrm{SO}_{4}$ occurred not from the components of the soil, but from those of the binders.

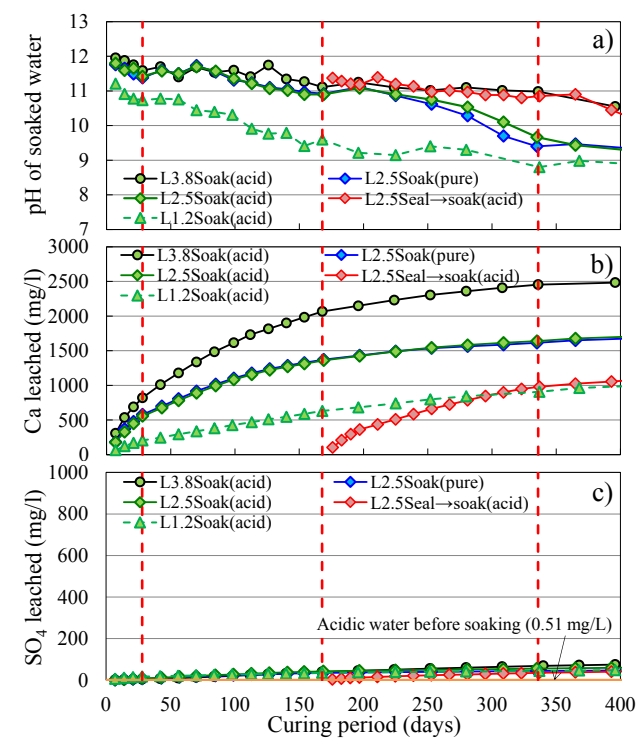

Fig. 9. Changes in a) $\mathrm{pH}$ value, accumulated amounts of b) $\mathrm{Ca}$ and c) $\mathrm{SO}_{4}$ in water after soaking of lime treated specimens.

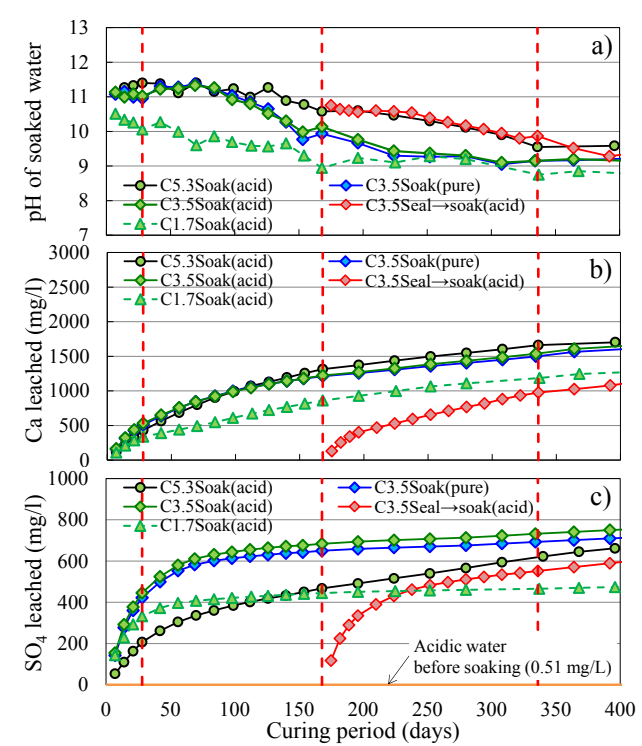

Fig. 10. Changes in a) $\mathrm{pH}$ value, accumulated amounts of b) $\mathrm{Ca}$ and c) $\mathrm{SO}_{4}$ in water after soaking of cement treated specimens. 
The relationships between the strength ratios, remaining ratios of $\mathrm{Ca}$ and $\mathrm{SO}_{4}$ on lime and cement treatments after 28, 168 and 336 days are shown in Fig. 11. Remaining ratio of $\mathrm{SO}_{4}$ on the lime treated soil was not evaluated, as the content of $\mathrm{S}$ on the quick lime in this study was equivalent to zero. In general, the strength ratios of both soils treated by lime and cement decreased with the decline of the remaining ratios of $\mathrm{Ca}$ and $\mathrm{SO}_{4}$. Lower remaining ratios of $\mathrm{Ca}$ and $\mathrm{SO}_{4}$ were obtained at a certain curing period when the cement contents were smaller in the case 2. Possible reason for this might be the higher permeability on the specimen with smaller cement content, due to larger pore structures. On the other hand, the remaining ratio of $\mathrm{Ca}$ indicated almost the same value in every curing periods, independent from the different strength ratios and the lime contents. Besides this, the remaining ratio of $\mathrm{SO}_{4}$ in the cases 2 and 3 were different at a certain level of strength ratio.

It was reported in the previous studies that leaching of $\mathrm{Ca}$ with a decrease in $\mathrm{pH}$ value caused the decline in strength of the improved soils [1-2, 9-10]. As introduced more in detail by the authors [8], it was also known that there were several possible states of $\mathrm{Ca}$ in the improved soils. Some of them were believed to be related with the strength of the soils highly. These are hereafter denoted as hydration products, such as $\mathrm{C}-\mathrm{S}-\mathrm{H}$ products (calcium silicate hydrates) and ettringite which is crystalized by $\mathrm{Ca}$, $\mathrm{Al}, \mathrm{SO}_{4}$ and $\mathrm{H}_{2} \mathrm{O}$. On the other hand, it was said that another states of $\mathrm{Ca}$ would be easier to be leached out.

According to the change in the strengths summarized in Figs. 5 and 6, qu values increased until 168 days even under the soaked curing on L3.8 and C5.3. With considering the results of the previous studies, it was supposed that the strength of the soaked specimens were given by the balance of positive effect such as additional reaction to hydration products and negative effect such as failure or dissolution of them, during long period of time. Amounts of the $\mathrm{Ca}$ and $\mathrm{SO}_{4}$ remained as the hydration products could be linked with the strength ratios more accurately. However, evaluations of the leached amount of $\mathrm{Ca}$ and $\mathrm{SO}_{4}$ dissolved into the water could not give us the amount of them. In addition to that, the effect of suction force on their strengths should also be quantified to clarify the effect of physical property more precisely. Further investigations will be conducted by introducing mineralogical analyses such as X-ray diffraction and thermogravimetric analysis to evaluate the amounts of hydration products. Water retention and permeability tests will also be conducted to understand suction force. Additionally, more specimens with larger curing periods will be tested with the same conditions.

\section{Summary}

The effect of environmental exposure conditions on the long term mechanical property of surplus soils improved by lime and cement was investigated.

As a result of the experiments after 1 year (336 days) from specimen preparation, the unconfined compressive strengths of the soaked specimens were found to be the smallest, while those of the sealed specimens with keeping unsaturated conditions were the largest.

Effect of soaking on the strengths appeared obviously in the cement treated soil, while the effect decreased when the duration of initial sealed curing increased.

One of the reason for the differences in the strengths of treated soils was detected as the changes in physical property such as degree of saturation. The other was estimated to be the changes in chemical property, due possibly to the leaching of hydration products during soaking.
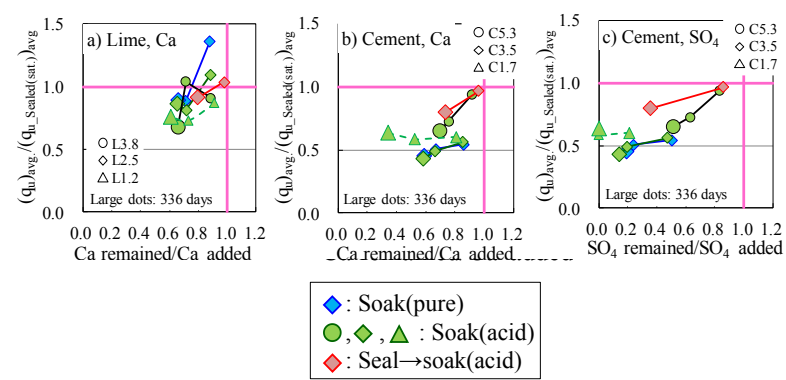

Fig. 11. Relationships between strength ratio, remaining ratios of $\mathrm{Ca}$ and $\mathrm{SO}_{4}$ on lime and cement treated soils.

This study was conducted in a collaborative research by Japan Cement Association, Japan Lime Association, the University of Tokyo, Fudo Tetra Corp., Fujita Corp., Hazama Ando Corp., Maeda Corp., Mikasa Sangyo Co., Ltd., Nishimatsu Construction Co., Ltd., Nishio Rent All Co., Ltd., Obayashi Corp., Sakai Heavy Industries, Ltd., and Public Works Research Institute. The authors would like to thank all of the participants for their insightful comments and suggestions.

\section{References}

1. M. Kitazume, T. Nakamura, M. Terashi, K. Ohishi, Proc. $3^{\text {rd }}$ Int. Conf. Grouting and Ground Treatment, ASCE, 586-597 (2003)

2. H. Takahashi, Y. Morikawa, N. Fujii, M. Kitazume, Proc. Inst. Civ. Eng. Ground Improvement, 1-13 (2017)

3. P. V. Ngoc, B. Turner, J. Huang, R. Kelly, $19^{\text {th }}$ Southeast Asian Geotech. Conf. (2016)

4. H. Hashimoto, T. Hayashi, H. Hayashi, 19 $9^{\text {th }}$ Southeast Asian Geotech. Conf., 361-366 (2016)

5. Y. Miyashita, G. Inoue, Conf. Deep Foundations and Ground Improvement, DFI-EFFC2018, 1151-1159 (2018)

6. Japan Lime Association, Ground improvement manual using lime (2018) (in Japanese)

7. Japan Cement Association, Ground improvement manual using cement-based product (2012) (in Japanese)

8. D. Sanjeewani, Y. Miyashita, R. Kuwano, A. Negishi, $6^{\text {th }}$ Int. Symp. Deformation Characteristics of Geomaterials, IS-Glasgow 2019 (to be published)

9. M. H. Ghobadi, Y. Abdilor, R. Babazadeh, Bull. Eng. Geol. and Env., 73 (2), 611-619, (2014)

10. M. Kamon, C. Ying, T. Katsumi, Soils and Found., 36, 4, 91-99 (1996) 